\title{
STRENGTHENING OF RCC STRUCTURES USING FRP COMPOSITE TECHNOLOGY
}

\author{
Divya Chandroth ${ }^{1}$, Lt Col Harshad Chati ${ }^{2}$, Gopal L Rai ${ }^{3}$ \\ ${ }^{1}$ Twenty First SHM Consultants Pvt Ltd, Mumbai, India \\ ${ }^{2}$ Twenty First SHM Consultants Pvt Ltd, Mumbai, India \\ ${ }^{3} R \&$ M International Pvt Ltd, Mumbai, India
}

\begin{abstract}
Fiber reinforced polymer (FRP) composites are gaining wide applications in retrofitting of Reinforced Cement Concrete (RCC) structures owing to its inherent advantages over other conventional methods of strengthening. It finds its use in strengthening of structures having deficiencies arising due to usage, design and other loading changes. The use of Fiber reinforced polymer (FRP) composites as externally bonded reinforcement in the strengthening and retrofitting of Reinforced Cement Concrete (RCC) structures has been presented in this paper. An approach on designing of structures based on the American Codal provisions of ACI.440.2R along with on-site applications has been outlined
\end{abstract}

Keywords: FRP, RCC, Bridges, Strengthening, Flexure, Shear, Retrofitting

\section{INTRODUCTION}

Conventional methods of strengthening are being replaced with the high strength composite fibres in the form of precured, precast and wet layup systems. These materials can be used in a variety of applications owing to its superior properties like high tensile strength, light weight, non magnetic, non corrosive and ease of application. Its use in comparison with other methods is economical as it does not require specialized construction equipments, machinery and requires less time for application on structures.

Fiber reinforced polymer composites comprises of high strength fibres and resin matrix. The high strength fibres act as the main load carrying member and the resin matrix acts as the fiber protecting and load transferring medium. Various experimental and analytical studies have been carried out to study the behaviour of FRP strengthened beams [1]. It has been found that an improvement of more than $59.3 \%$ in load carrying capacity in slabs is obtained when strengthened with FRP [2]. FRP application on column results in increase in ductility and axial load carrying capacity [3]. The use of FRP has increased worldwide but there are limited Codal guidelines available for the design of FRP system for strengthening of RCC structures. The studies carried out on the FRP design and detailing have resulted in its application to strengthen important structures [4].

\section{DESIGN APPROACH ON THE USE OF FRP}

Design approach as per American Codal provisions [5] is based on limit state method and it takes into consideration the inherent strengthening limits of the structure while designing. Strengthening limits of the structural member being strengthened is considered such that the structure should have inherent strength to resist considered load as per equation below:-

$$
\left(\phi R_{n}\right)_{\text {existing }} \geq\left(1.1 S_{D L}+0.75 S_{L L}\right)_{\text {new }} \ldots
$$

Environmental effects are considered and appropriate reduction factors are applied to the material properties in the design equations. FRP materials show degradation when exposed to environmental factors such as humidity, alkalinity, high temperature, chemicals, UV light and cyclic loading. The ultimate tensile strength and design rupture strain are arrived at after consideration of the environmental reduction factors according to the equations given below:-

$$
f_{f u}=C_{E} f_{f u}^{*}
$$

$\&$

$$
\varepsilon_{f u}=C_{E} \varepsilon_{f u}^{*}
$$

\subsection{Design for Flexural Strength Enhancement}

Enhancement in flexural strength can be achieved when the FRP laminates are placed along the tension face of the structural members. The design for flexural enhancement is based on the Principles of Limit State of Design and on assumptions [5] as given below:-

- There exists a perfect bond between the FRP composites and concrete with no relative slip between the FRP materials and parent concrete

- Plane section before loading remains plane after loading

- Shear deformation within adhesive layer is neglected 
- FRP reinforcement has linear elastic stress strain relationship upto failure

The strengthening design is carried out such that the strength after FRP strengthening should be greater than the required strength. Thus,

$$
\phi M_{n} \geq M_{u}
$$

In the design approach it should be ensured that the stress in FRP and steel reinforcement under service conditions does not exceed the limits as stipulated by Codal provisions.

\subsection{Design for Shear Strength Enhancement}

Shear strength enhancement in structures can be done by providing FRP wrapping either on three sides or on all sides of the structural member. The direction of fibres is in 45 or 90 degrees to the longitudinal axis of the member. Proper anchorage of the FRP wraps is provided in the compression zone of the structural members by providing anchors. The design shear strength of the FRP strengthened beams should be greater than the strength required due to deficiency in the structural member and governed by the following equation :-

$$
\phi V_{n} \geq V_{u}
$$

where,

$$
\phi V_{n}=\phi\left(V_{c}+V_{S}+\psi_{f} V_{f}\right)
$$

It has been found by researchers that the maximum enhancement in shear strength is obtained by wrapping the FRP on all the sides of the member followed by wrapping on the three sides of member [5].

\subsection{Design for Axial Strength Enhancement}

Strengthening of compression members for axial load enhancement is provided by confining the columns with FRP wraps in a hoop direction with the direction of fibres in 90 degrees to the longitudinal axis of the members. This enhances the confinement in columns thus leading to enhancement in axial load carrying capacity of columns and ductility. It has been found from experimental research that the efficiency in confining action of FRP in case of round columns is more than that of square or rectangular columns [6]. The increase in capacity calculation of rectangular columns is restricted to the percentile of area of the column as confined with FRP, unlike circular columns where full area confinement is achieved. The confined peak strength in columns strengthened with FRP and the corresponding strain as per Mander confinement model is governed by the following equations:-

$$
f_{c c}=f_{c o}\left(2.254 \sqrt{1+7.94 \frac{f_{l}}{f_{c o}}}-2 \frac{f_{l}}{f_{c o}}-1.254\right)
$$

$\varepsilon_{c c}=\varepsilon_{c o}\left[1+5\left(\frac{f_{c c}}{f_{c o}}-1\right)\right]$

Fibres are chosen in strengthening of columns as governed by the requirement. Glass and aramid fibres are used when increase in ductility is required and carbon is used when increase in strength is required in the axial member.

\section{RECENT ADVANCES IN THE USE OF FRP}

Active Strengthening System have been developed and tested for flexural and axial strength enhancement in structural members. In this method, pre strengthening of the FRP materials is done through an application of force. Prestressing of FRP laminates and FRP fiber wraps are active strengthening measures in use for improving the performance of FRP composite on the structure. It improves the serviceability of a structure by reducing cracks and deflections in the structural members. There are methods to enhance flexural strength of members by providing prestress in the FRP laminates [7]. The amount of prestress given to FRP laminate is governed by the requirement and existing structural member capacity. The excessive prestress can lead to premature failure of the structural member. To prevent delamination anchorages need to be provided at the ends of the laminates for effective transfer of prestressing forces.

\section{CASE STUDIES}

\subsection{Strengthening of ROB at Karal Junction due to}

\section{change in Loading}

ROB at Karal junction of JNPT having a span of $700 \mathrm{~m}$ required strengthening as it showed deterioration with time. The bridge was originally designed for Class 45R loading and as per revised Codal provisions the bridge was required to sustain Class $70 \mathrm{R}$ loading. Excessive deflections, vibrations and cracks were observed in girders of 36 spans of the bridge. Flexural and shear cracks were observed in the girders. In order to strengthen the distressed girders the FRP composite system were applied. After initial crack repair of the structure prestressed CFRP laminates with a prestressing force of 8 ton were applied at the bottom of the girder for enhancing the flexural strength. For enhancement of the shear strength carbon fiber composite wrapping was carried out. After the structural strengthening of the spans static and dynamic load testing on the strengthened span were carried out [9]. Fourteen spans of the bridge were subjected to monitoring for before and after strengthening. Monitoring of deflection, flexural strain, shear strain and vibration were carried out by installing sensors, LVDT, data logger and acquired data was processed. It was observed that post strengthening there was improvement in the parameters observed earlier. There were reduction to the tune of $26 \%$ in deflection, $53 \%$ in flexural strain and $56.8 \%$ in shear strain were observed [9]. 


\subsection{Strengthening of Skew Slab of Bridge due to} distress in Slab due to change in Load

A skew slab bridge at a flyover in Bangalore required strengthening due to change in loading and distress observed in the slab. The skew slab showed sagging and cracks were observed. The cracks were filled with epoxy injection grouting and FRP composite technology was applied for strengthening of the slab. Prestressed CFRP laminates were used at the bottom of slab to enhance its load carrying capacity.

\subsection{Strengthening of ROB at Markapur due to \\ Deficiency in Steel Reinforcement}

An ROB at Markapur required strengthening owing to the deficiency in steel reinforcement in the slab. The deficiency led to distress and cracks in the deck slab.FRP composite system were applied for making up the deficiency. Non Prestressed FRP laminates were placed at the bottom of slab for enhancement in strength. Load testing on the bridge deck was done for validation of design. Two testing vehicles of loading capacity 41.5 Ton each were placed on the deck slab both for static load conditions. Deflections and strain measurement were carried out both before and after strengthening. There was an improvement in measuring parameter by $59.33 \%$ as observed.

\section{CONCLUSION}

This paper details on the use of FRP in strengthening of structures. It details on the design of FRP along with its real life applications. Strengthening using both prestressed and non prestressed FRP laminates for enhancement in flexural strength of RCC structures has been elucidated along with its application.

\section{NOTATION}

$C_{E}=$ Environmental reduction factor

$f_{c c}=$ Confined concrete strength $\left(\mathrm{N} / \mathrm{m}^{2}\right)$

$f_{c o}=$ Unconfined concrete strength $\left(\mathrm{N} / \mathrm{m}^{2}\right)$

$f_{f u}=$ Design ultimate tensile strength of FRP (in N/ $\mathrm{m}^{2}$ )

$f_{f u}^{*}=$ Ultimate tensile strength of the FRP material as given by manufacturer (in $\mathrm{N} / \mathrm{m}^{2}$ )

$f_{l}=$ Maximum Confining stress (in $\mathrm{N} / \mathrm{m}^{2}$ )

$M_{n}=$ Nominal flexural strength (in N-m)

$M_{u}=$ Factored moment at a section (in N-m)

$S_{D L}=$ Dead load effect

$S_{L L}=$ Live load effect

$\left(\phi R_{n}\right)_{\text {existing }}=$ the factored nominal strength of the member existing

$V_{C}=$ Nominal shear strength provided by concrete with steel flexural reinforcement (in $\mathrm{N}$ )
$V_{f}=$ Nominal shear strength provided by FRP stirrups (in $\mathrm{N})$

$V_{n}=$ Nominal shear strength (in $\mathrm{N}$ )

$V_{S}=$ Nominal shear strength provided by steel stirrups (in $\mathrm{N})$

$V_{u}=$ Required shear strength at a section (in $\mathrm{N}$ )

$\varepsilon_{c c}=$ Compressive strain at confined peak strength $f_{c c}$ (in $\mathrm{m} / \mathrm{m})$

$\varepsilon_{c o}=$ Initial concrete strain in the extreme compressive fibre before strengthening, or

Unconfined concrete strain at peak stress (in $\mathrm{m} / \mathrm{m}$ )

$\varepsilon_{f u}=$ Design rupture strain of FRP reinforcement (in $\mathrm{m} / \mathrm{m}$ )

$\varepsilon_{f u}^{*}=$ Ultimate rupture strain of FRP reinforcement (in $\mathrm{m} / \mathrm{m})$

$\phi=$ Strength reduction factor

$\psi_{f}=$ FRP strength reduction factor

\section{REFERENCES}

[1] Prashanth, M. H., Suraj. K, Babu Narayan, K. S, and Ravikumar, C. M., "Performance Enhancement of Preloaded RC beams using CFRP sheets", International Journal of Earth Sciences and Engineering, Proc., V. 05, No. 06 (01), Dec. 2012, pp. 1715 - 1719

[2] Florut, S. C., Stoion, V., Gyorgy, T. N., Dan, D and Diaconu, D., " Retrofitting of two-way RC slabs with and without cut-out openings by using FRP composite materials", Latest Trends on Engineering Mechanics, Structures, Engineering Geology, pp. 245 - 250

[3] Sheikh, S. A and Yimin. L., " Design of FRP confinement for square concrete column", Enginnering structures 29 (2007), pp. 1074 - 1083

[4] Irwin, R and Rahman, A., "FRP strengthening of concrete structures - Design constraints and practical effects on construction detailing", New Zealand Concrete Society Conference 2002., Section. 4 Paper 2

[5] ACI Committee 440, "ACI 440.2R-08, Guide for the design and construction of externally bonded FRP systems for strengthening concrete structures", American Concrete Institute, 2008

[6] Task group 9.3, "FRP Externally bonded FRP reinforcement for RC structures", fib CEB-FIP, Technical report bulletin 14, 2001

[7] El-Hacha, R., Wright, R. G and Green, M. F., “ Prestressed fiber-reinforced polymer laminates for strengthening structures" , Prog. Struct.Engng Mater.2001, V. 3,2001, pp. 111-121

[8] Dr. Rai, G., "Pre-stressing Techniqiues for structural strengthening using FRP composites", The Masterbuilder, May 2013, pp. 200-202

[9] Rai, G.L and Bambole, A. N., "Strengthening of bridge by Pre-Stressing at JNPT and testing its efficacy", ACI Fall 2010 Convention ACI SP 285, (2010). 


\section{PHOTOGRAPHS}

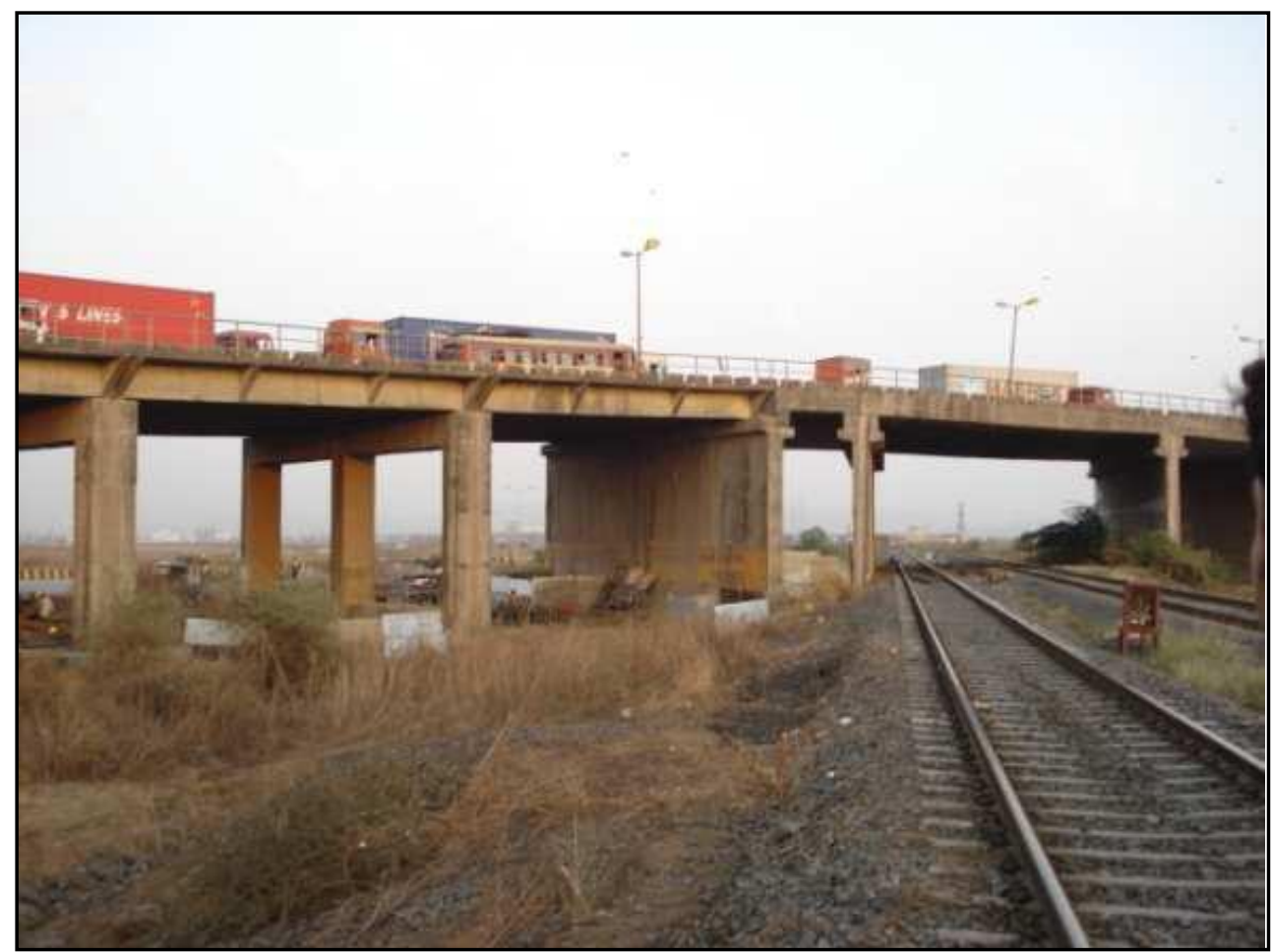

Fig. 1 Rail Over Bridge (ROB) at JNPT [9]

(Courtesy:- M/s R \& M International Pvt Ltd)

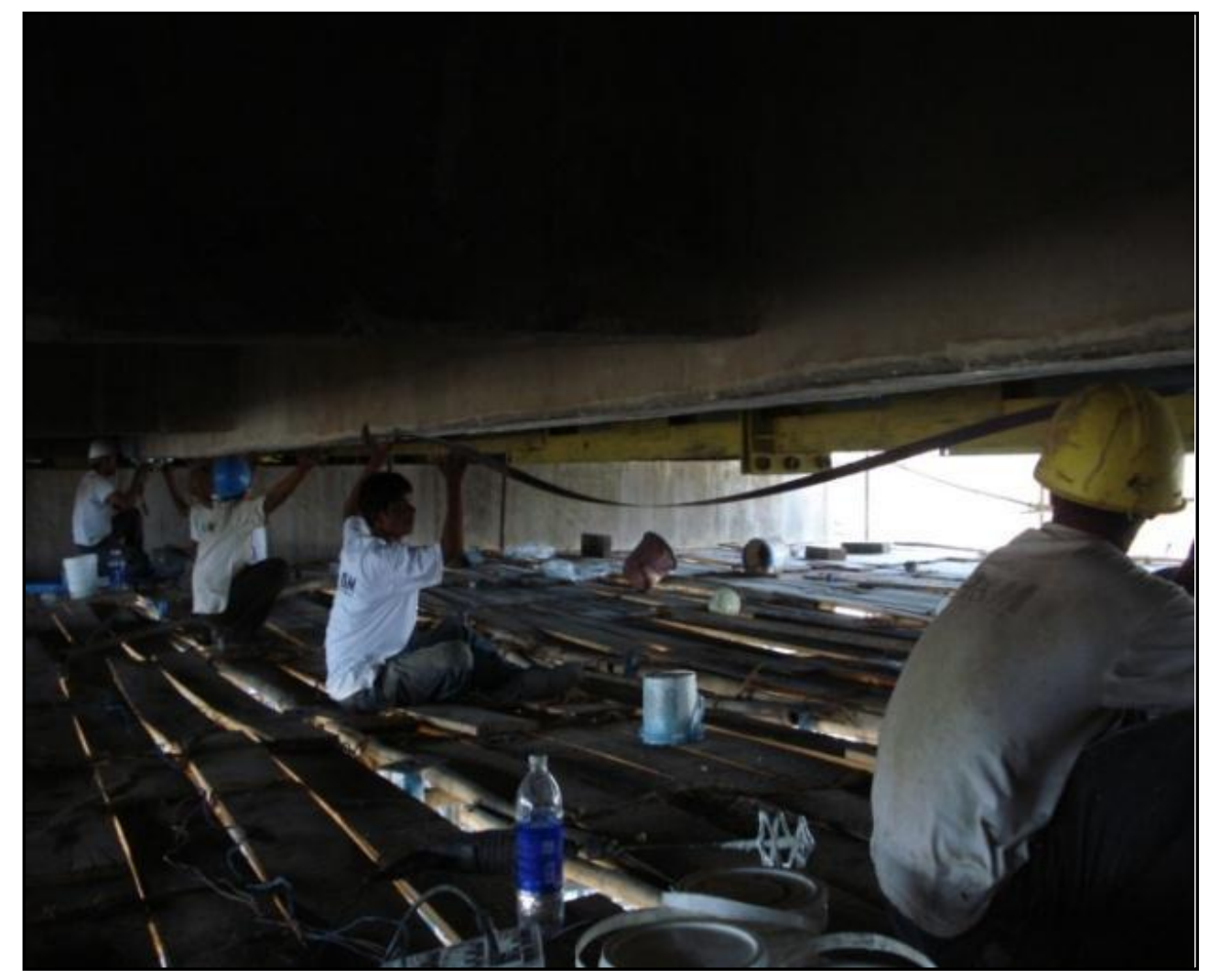

Fig.2 Bottom of girder with Prestressing of CFRP laminates in process [9] (Courtesy:- M/s R \& M International Pvt Ltd) 


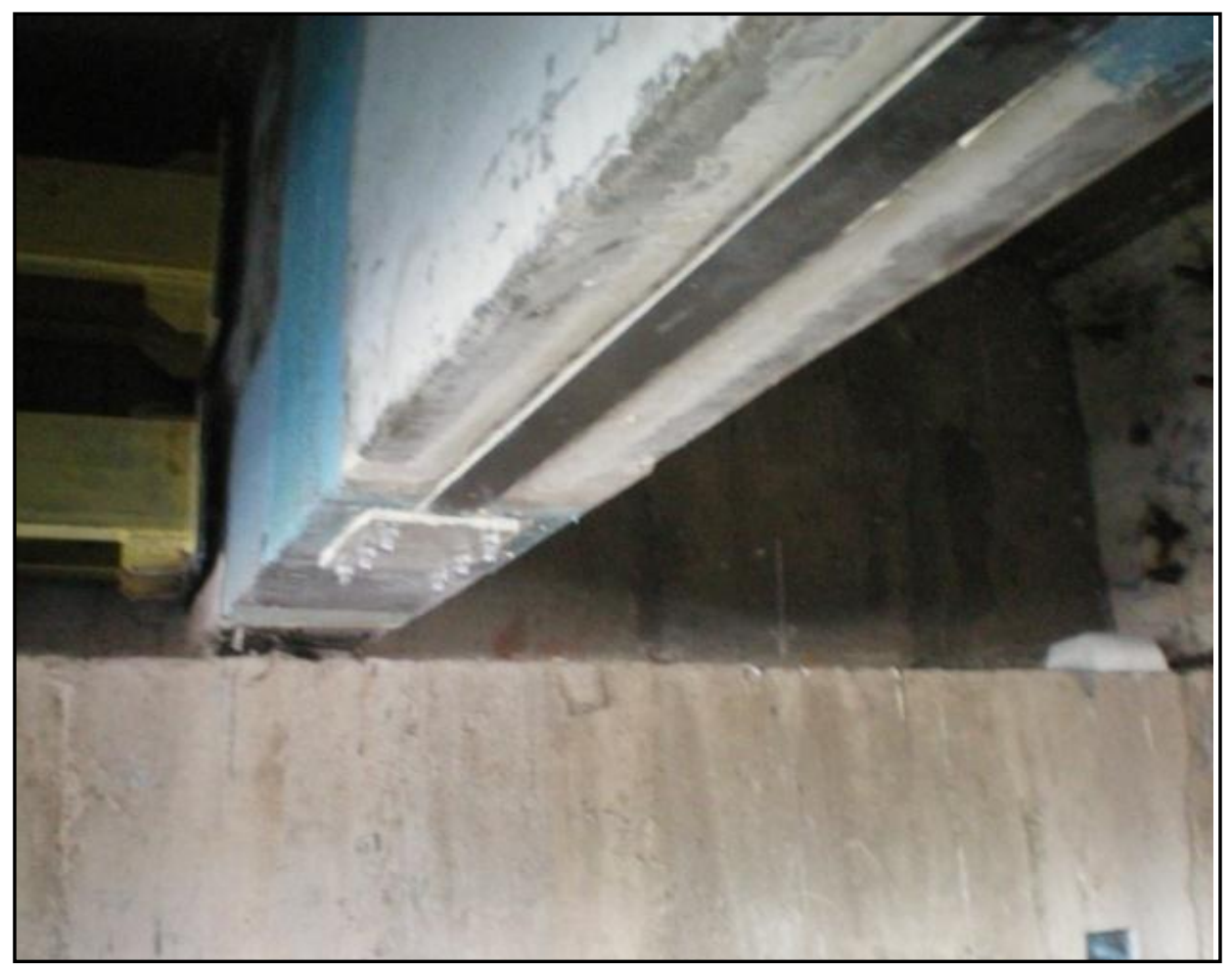

Fig. 3 CFRP prestressed laminates in girders [9] (Courtesy:- M/s R \& M International Pvt Ltd)

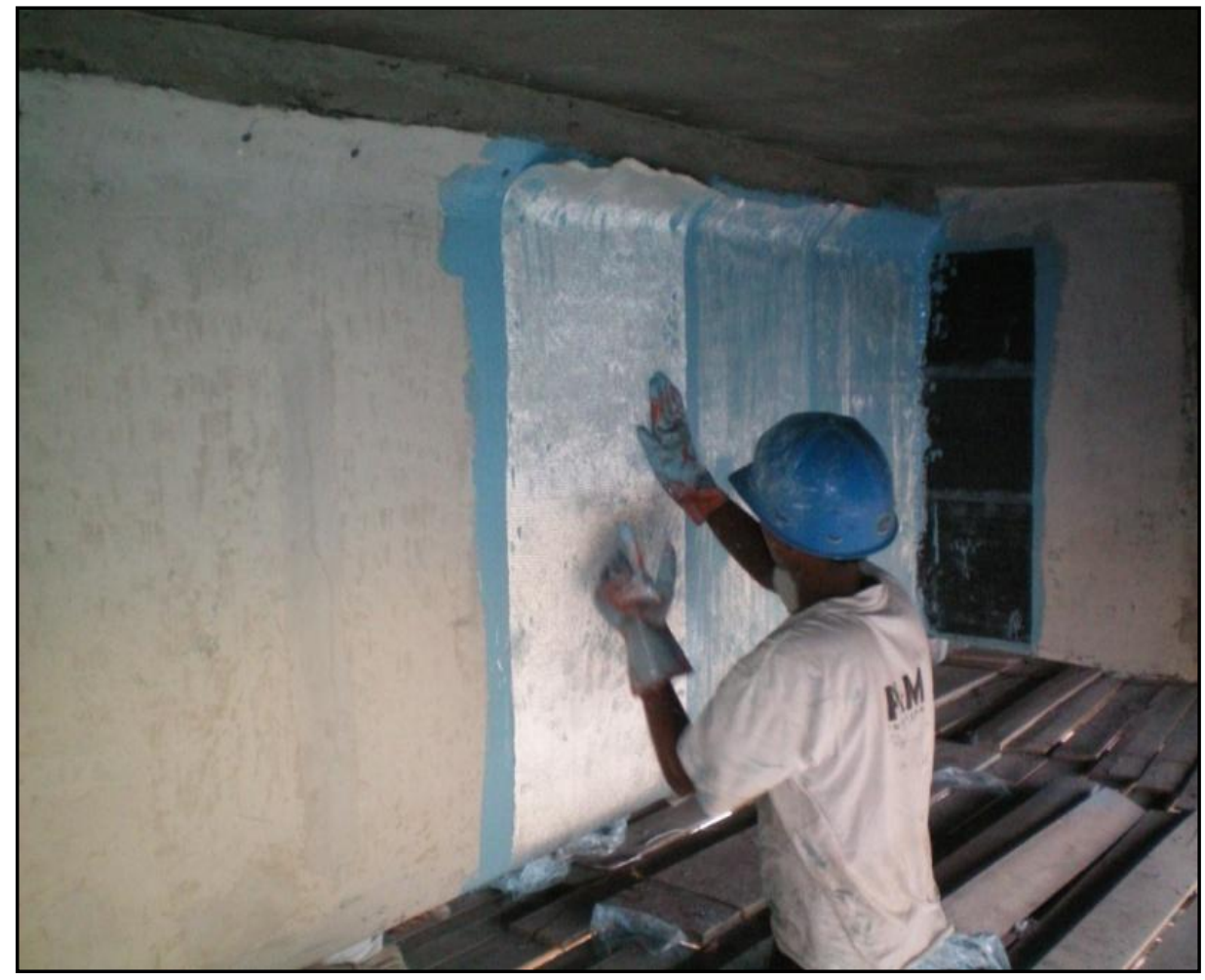

Fig. 4 FRP application on girder for shear strength increase (Courtesy:- M/s R \& M International Pvt Ltd) 


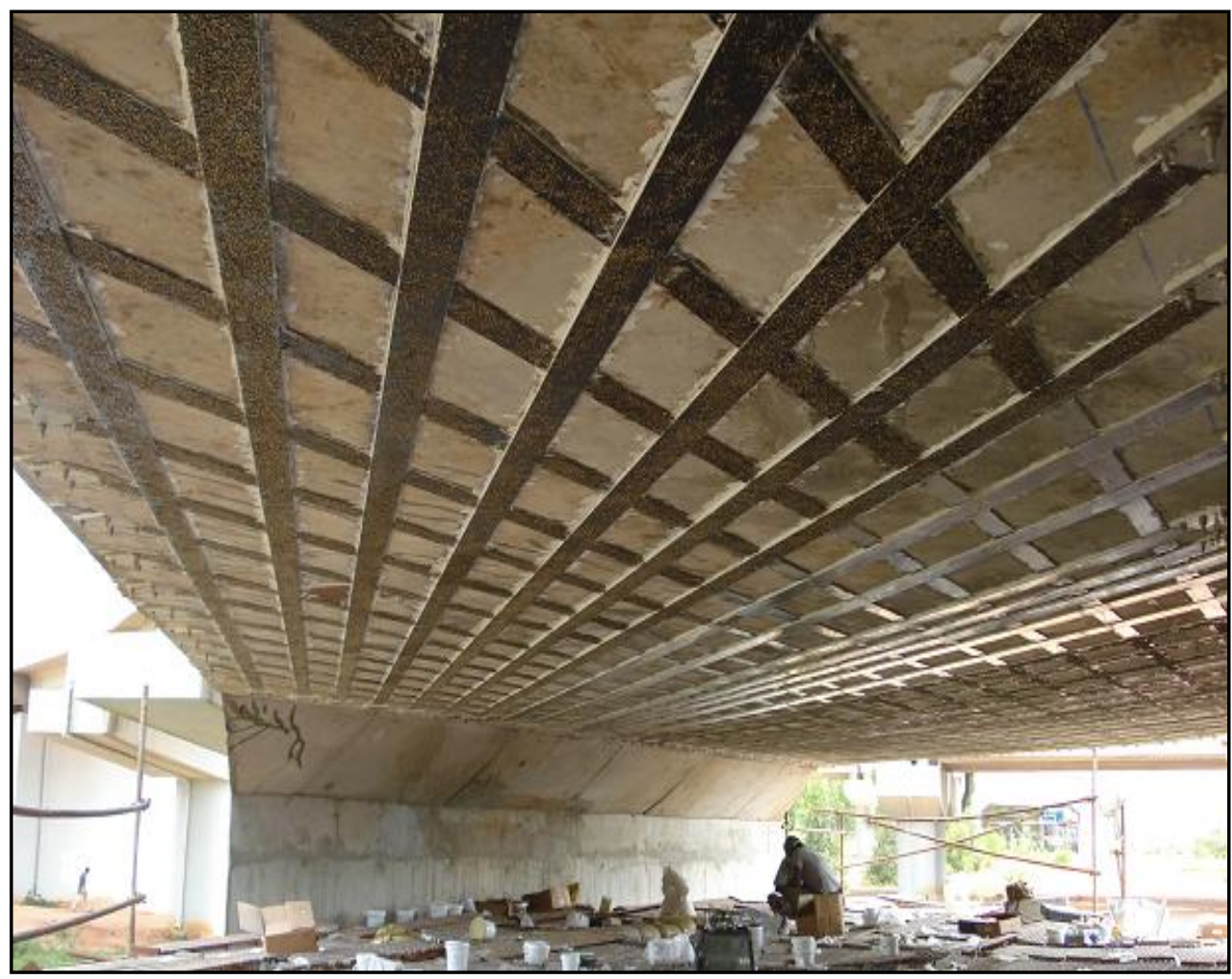

Fig. 5 Prestressed FRP laminates at bottom of skew slab bridge (Courtesy:- M/s R \& M International Pvt Ltd)

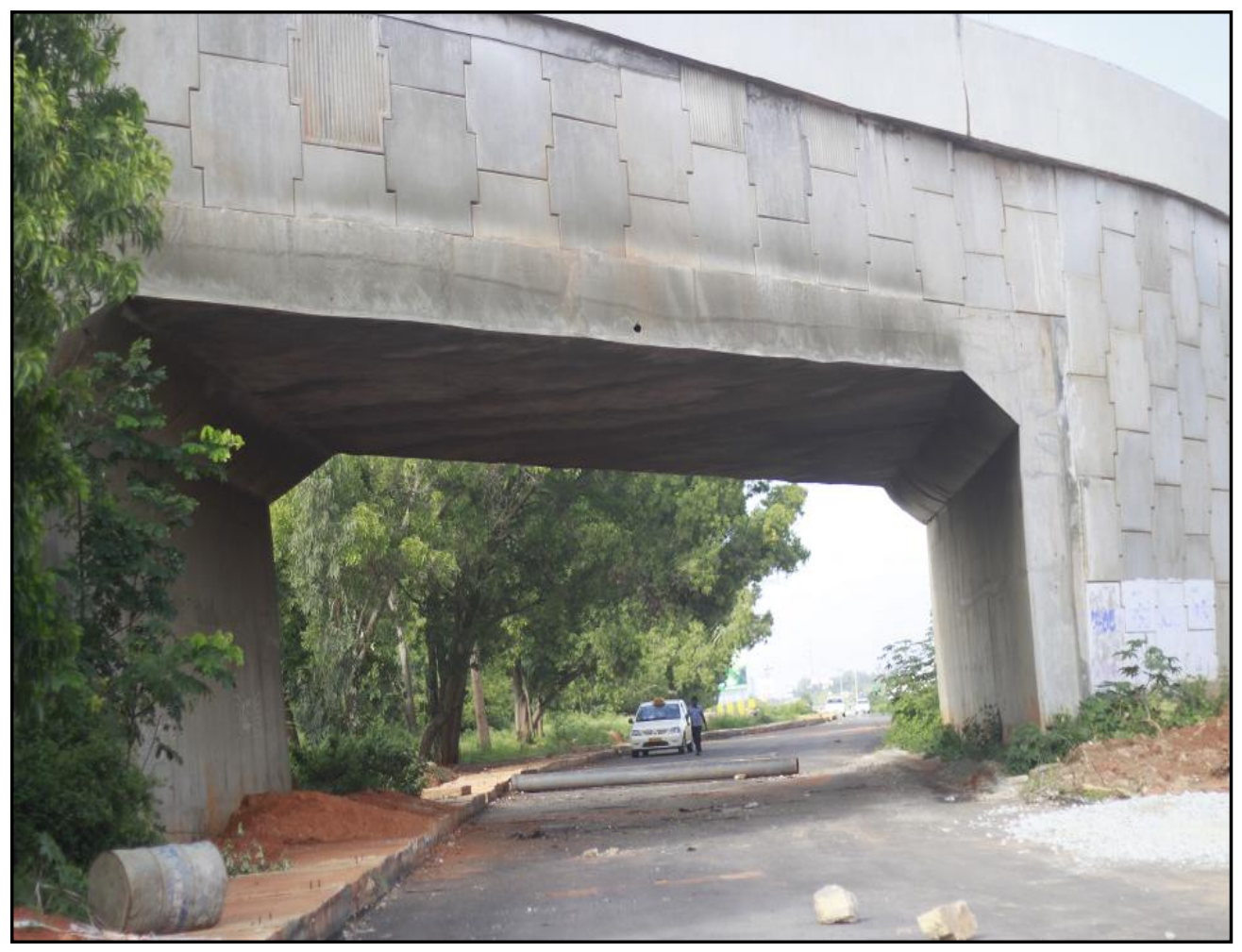

Fig. 6 Post strengthening of skew Slab Bridge (Courtesy:- M/s R \& M International Pvt Ltd) 


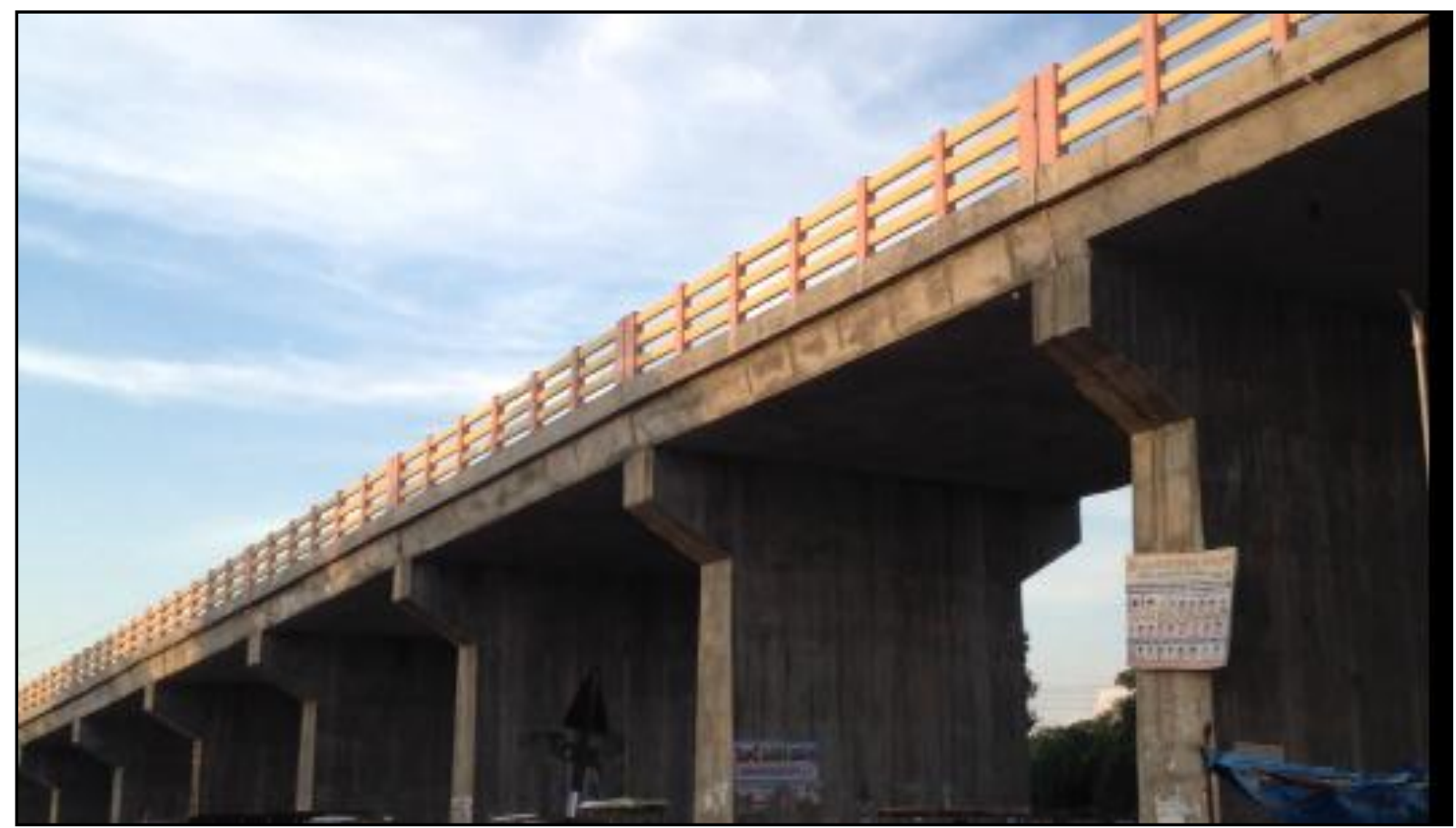

Fig. 7 ROB at Markapur requiring strengthening (Courtesy:- M/s R \& M International Pvt Ltd)

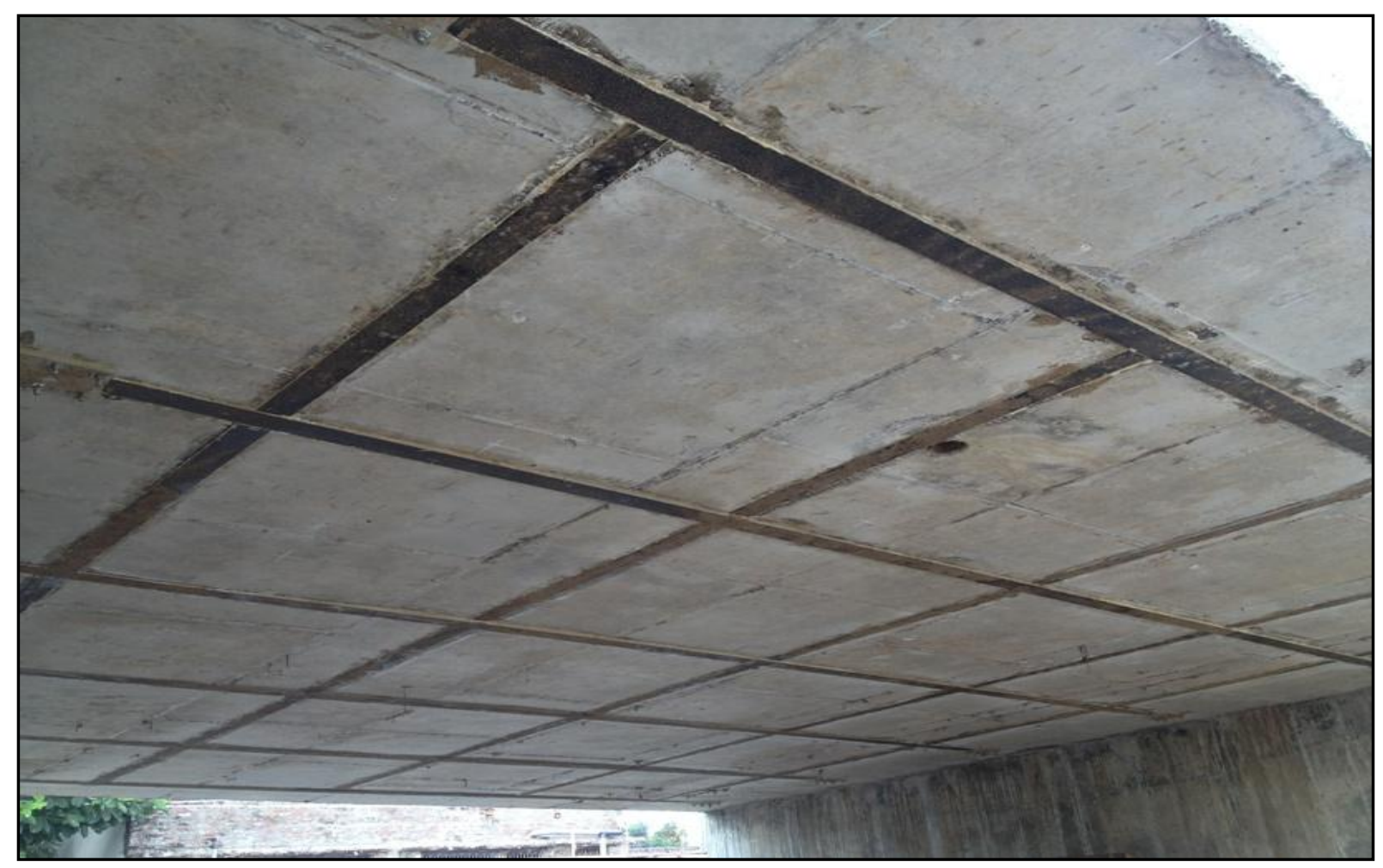

Fig. 8 Strengthening with Non Prestressed FRP laminates at bottom of slab of ROB at Markapur (Courtesy:- M/s R \& M International Pvt Ltd) 


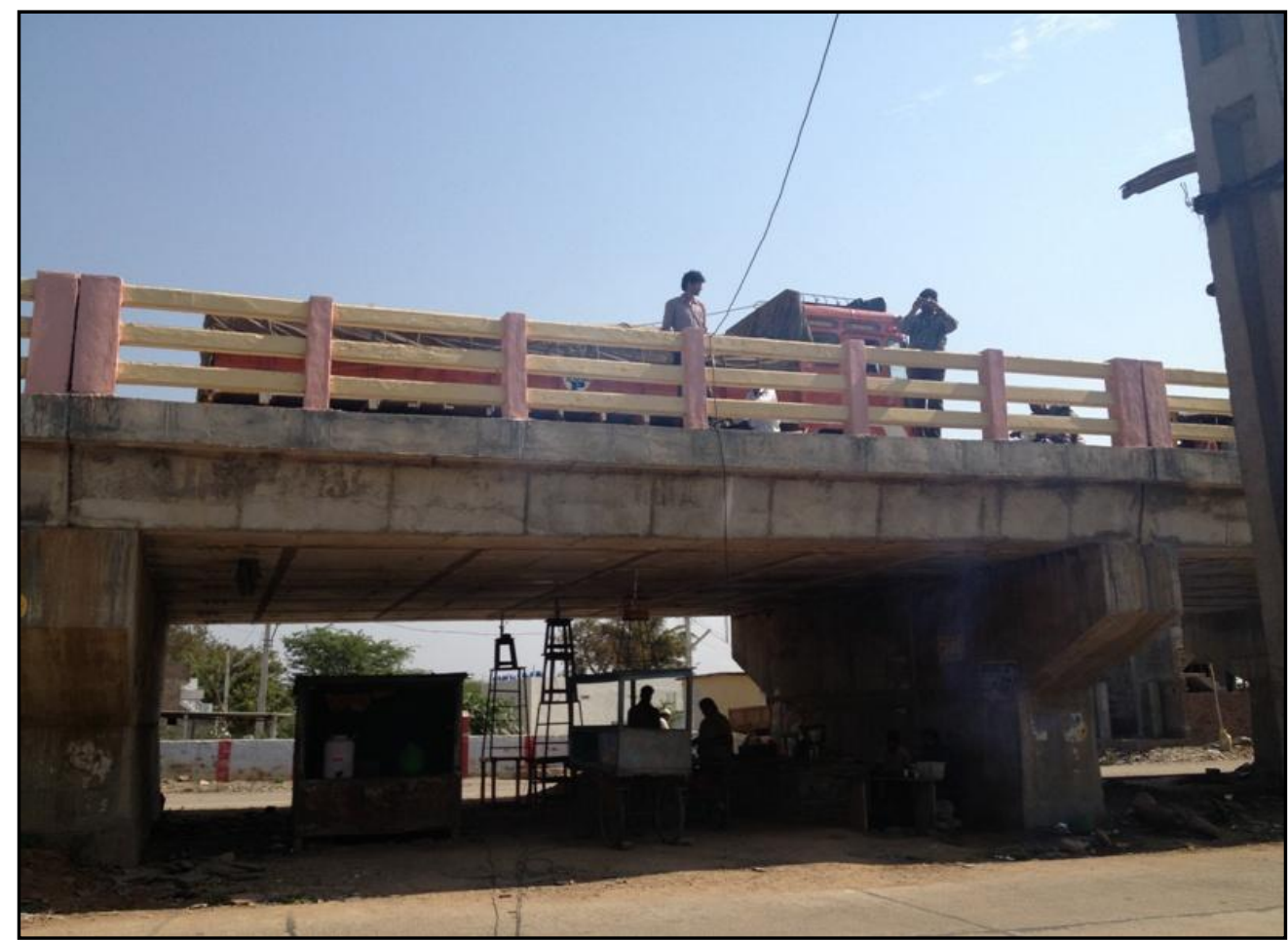

Fig. 9 Load test being carried out post strengthening of ROB at Markapur (Courtesy:- M/s R \& M International Pvt Ltd) 